\title{
Integrated Study of the Dinitrobenzene Electroreduction Mechanism by Electroanalytical and Computational Methods
}

\author{
Andrey S. Mendkovich, ${ }^{1}$ Mikhail A. Syroeshkin, ${ }^{1}$ Ludmila V. Mikhalchenko, ${ }^{1}$ \\ Mikhail N. Mikhailov, ${ }^{1}$ Alexander I. Rusakov, ${ }^{2}$ and Vadim P. Gul'tyai ${ }^{1}$ \\ ${ }^{1}$ N.D. Zelinsky Institute of Organic Chemistry, Russian Academy of Sciences, Moscow 199991, Russia \\ ${ }^{2}$ P.G. Demidov Yaroslavl State University, Yaroslavl 150000, Russia \\ Correspondence should be addressed to Andrey S. Mendkovich, asm@free.net
}

Received 19 July 2010; Revised 20 September 2010; Accepted 20 September 2010

Academic Editor: Jay D. Wadhawan

Copyright ( 2011 Andrey S. Mendkovich et al. This is an open access article distributed under the Creative Commons Attribution License, which permits unrestricted use, distribution, and reproduction in any medium, provided the original work is properly cited.

\begin{abstract}
Electroreduction of 1,2-, 1,3-, and 1,4-dinitrobenzenes in DMF has been investigated by a set of experimental (cyclic voltammetry, chronoamperometry, and controlled potential electrolysis) and theoretical methods (digital simulation and quantum chemical calculations). The transformation of only one nitro group is observed in the presence of proton donors. The process selectivity is provided by reactions of radical anions' intermediate products. The key reactions here are protonation of radical anions of nitrosonitrobenzenes and $\mathrm{N}-\mathrm{O}$ bond cleavage in radical anions of $\mathrm{N}$-(nitrophenyl)-hydroxylamines.
\end{abstract}

\section{Introduction}

Electrochemical reduction of organic compounds to include a transfer of one or two electrons onto the substrate molecule is known to be accompanied by the formation of corresponding radical anions (RAs) and dianions (DAs) [1]

$$
\mathrm{A} \underset{E_{1}^{0^{\prime}}}{\stackrel{e^{-}}{\longrightarrow}} \mathrm{A}^{\cdot-} \underset{E_{2}^{0^{\prime}}}{\stackrel{e^{-}}{\longrightarrow}} \mathrm{A}^{2-}
$$

Reactivity of these particles is much higher than that of initial neutral compounds and their reactions are noted for the diversity [2]. This, on the one hand, makes the use of RA and DA beneficial for the organic synthesis and, on the other hand, impedes affording selectivity of processes with their involvement. That is why a research on RA and DA reactions is of high relevance. State-of-the-art electroanalytical methods show promise in addressing this issue because they allow both a ready RA and DA generation and investigation of their reaction kinetics. It should be noted that eletroanalytical methods in combination with other experimental (e.g., controlled potential electrolysis) and theoretical methods such as digital simulation and quantum chemistry offer high opportunities for the studies on the mechanism of electrochemical processes and development of their theoretical models. We have employed such integrated approach for investigating electroorganic reactions in a series of researches over a few past years [3-7].

Electroreduction of mono- [8] and polynitroaromatic [9] molecules in the proton donor medium is an example of a complex electrochemical process running through the RA and DA formation steps, which is both of theoretical and of practical interest. An important objective of applied nature in polynitroaromatics chemistry is the development of techniques for selective reduction of one of the nitro groups while retaining the others [10-14]. However, as distinct from mononitro compounds whose electroreduction has been researched in reasonable detail [15], no systematic efforts have been so far made to identify factors that govern selectivity of this process.

This paper discusses a study on the mechanism of electrochemical reduction of dinitrobenzene isomers in the aprotic solvent (DMF) under the conditions of the formation of corresponding RA and DA with controlled amounts of various proton donors. 


\section{Experimental}

2.1. Instrumentation and Experiment Techniques. Chronoamperometry (CA), cyclic voltammetry (CV), and controlled potential electrolysis were implemented on a computer-assisted potentiostat IPC-Pro manufactured by Econix (sweep rate error $1.0 \%$, potential setting device $0.25 \mathrm{mV})$.

The experiments were performed in a $10 \mathrm{~mL} 5$-neck glass conic electrochemical cell with a water jacket for thermostating. Polarized curves were recorded using a threeelectrode scheme. Operating electrodes were a disc carbositall electrode (a glass-carbon electrode analog [16]) $(S=$ $\left.7.50 \mathrm{~mm}^{2}\right)$ and a disc platinum electrode $\left(S=0.1134 \mathrm{~mm}^{2}\right)$. A platinum net was utilized as a cathode for the electrolysis. A platinum wire (insulated by a ceramic membrane in electrolyses) served as an auxiliary electrode. A saturated calomel electrode (SCE) was used as the reference electrode. It was linked to the solution by a bridge with a porous ceramic diaphragm filled with background electrolyte $(0.1 \mathrm{M}$ $\mathrm{Bu}_{4} \mathrm{NClO}_{4}$ solution in DMF). For the CA and CV curves analysis, the values of current in the presence of the substrate were corrected for current of the background electrolyte at this potential.

Uncompensated resistance in the cell was measured using the $\mathrm{CV}$ curves of ferrocene electrooxidation in the same background electrolyte, varying its concentration and the potential scan rate in a similar manner as in [17]. Uncompensated resistance in the typical case was $417 \mathrm{Ohm}$, where the operating carbositall electrode was used and $4135 \mathrm{Ohm}$ with the platinum electrode. The area of operating electrodes was also determined by simulation of the $\mathrm{CV}$ curves of ferrocene electrooxidation (the ferrocene diffusion factor in DMF is known [18]).

Formal potentials of the transfer of one or two electrons to the substrate molecules were calculated from the half-sum of potentials of appropriate cathode and anode peaks on the $\mathrm{CV}$ curves in the conditions of their reversible reduction and with account of uncompensated resistance.

The tested solutions were thermostated at $25 \pm 0.1^{\circ} \mathrm{C}$. Deaeration of solutions was performed by argon passing through. To avoid a possible contact of the solution surface with the ambient air during the experiment argon was constantly fed to the cell's free space above the solution surface. In the typical case, $5 \mathrm{~mL}$ solution was utilized.

For the quantitative estimation of the electrolysis products by HPLC, a catholyte sample was taken and dissolved with the mobile phase in a measuring flask (the tested substances concentration $\left.10^{-6}-10^{-5} \mathrm{M}\right)$. Acetonitrile mixtures $1: 1,1: 3$ and, $1: 4$ and $0.1 \mathrm{M}$ phosphate buffer with $\mathrm{pH}=3$ were used as a mobile phase. Chromatography was performed in the phase-reversed conditions using a column filled with a nonpolar sorbent Diasfer-110-S16 $(5 \mu \mathrm{m}, 2.0 \times$ $80 \mathrm{~mm}$ ). UV detector operating wavelengths were 235 and $350 \mathrm{~nm}$. The electrolysis products were estimated by the area of the chromatogram peaks and their comparison with the calibration curve built basing on peak areas of standard concentration samples.
2.2. Research Subjects and Reagents. The structure of the tested compounds and appropriate legends are given in Scheme 1. 1,2-, 1,3-, and 1,4-DNB; 2-, 3-, and 4-NA manufactured by Reanal were utilized. All the reagents were of the p.a. grade and were recrystallized several times before use. Tetrabutylammonium perchlorate, 1-butyl-3methylimidazolium tetrafluoroborate, DMF ("extra dry" grade), and acetonitrile ("for HPLC" grade) were supplied by Acros Organics.

2-NNB were prepared by 2-NA oxidation according to [19], 3-NNB-by 1,3-DNB reduction to the hydroxylamino intermediate and its further oxidation by ferric (III) chloride [20], and 4-NNB - by 4-NA oxidation according to [21]. All products were distilled with vapor and recrystallized several times. 2- and 4-NPHA were prepared by reduction of 1,2and 1,4-DNB, respectively, according to [22], 3-NPHA by 1,3-DNB electroreduction according to [23]. 3,3'- and $4,4^{\prime}-\mathrm{DNAB}$ were prepared by oxidation of 3 - and $4-\mathrm{NA}$, respectively, according to [19].

2.3. Theoretical Calculations. Digital simulations of the current-voltage and current-time curves were carried out using DigiElch Professional, version 3 (Build 3.600) from ElchSoft [24]. The computation of model curves for the small-diameter operating electrode took in account the edge effect.

The calculation results were used for construction of the simulated 3D response function surface versus operating and intrinsic parameters. The value of the intrinsic parameter (rate constant) can be found from experimental values of the operating parameters and response function (Figure 1). The operating parameter varied over a range of values providing a maximum possible change of the response function value. In this work, an apparent number of electrons $\left(n_{\mathrm{app}}\right)$ was used as a response function and ratio of the proton donor concentration to the substrate concentration $(R)$ as operating parameter. In case of CV together with $R$, a scan rate was used as second operating parameter.

The approach described above was applied both to $\mathrm{CV}$ and to CA. It was shown that $\mathrm{CV}$ and $\mathrm{CA}$ provided rather good similarity of the results. For example, rate constants of 1,3-DNB DA protonation by the 1-butyl-3methylimidazolium cation measured in the $\mathrm{CV}$ and $\mathrm{CA}$ experiments were $100 \pm 30 \mathrm{M}^{-1} \mathrm{~s}^{-1}$ and $82 \pm 6 \mathrm{M}^{-1} \mathrm{~s}^{-1}$, correspondingly (Figure 2). It is seen that the difference in the values is comparable with $\mathrm{CV}$ data dispersion. It is worth pinpointing that CA provides better results in terms of dispersion.

For simplification, homogeneous redox reactions of dianion with neutral molecules of DNB as well as with intermediate products were neglected in calculations of response function surfaces. The adequacy of this approximation is based on the following. These reactions competing with protonation of dianion are reducing its concentration [25] which, in its turn, should result in reducing of the apparent value of the protonation rate constant $\left(\Delta k^{\text {prot }}\right)$. The results of the simulation have demonstrated that $\Delta k^{\text {prot }}$ becomes larger with increasing of $R$. Consequently, the plots of the 
<smiles>O=[N+]([O-])c1ccccc1[N+](=O)[O-]</smiles>

$1,2-\mathrm{DNB}$<smiles>O=[N+]([O-])c1cccc([N+](=O)[O-])c1</smiles>

1,3-DNB<smiles>O=[N+]([O-])c1ccc([N+](=O)[O-])cc1</smiles>

1,4-DNB<smiles>O=[N+]([O-])c1ccccc1[N+](=O)[O-]</smiles>

2-NNB<smiles>O=[N+]([O-])c1cccc([N+](=O)[O-])c1</smiles>

3-NNB<smiles>O=[N+]([O-])c1ccc([N+](=O)[O-])cc1</smiles>

$4-\mathrm{NNB}$<smiles>O=[N+]([O-])c1ccccc1NO</smiles>

2-NPHA<smiles>O=[N+]([O-])c1cccc(NO)c1</smiles>

3-NPHA<smiles>O=[N+]([O-])c1ccc(NO)cc1</smiles>

4-NPHA<smiles>Nc1ccccc1[N+](=O)[O-]</smiles>

2-NA<smiles>Nc1cccc([N+](=O)[O-])c1</smiles>

3-NA<smiles>Nc1ccc([N+](=O)[O-])cc1</smiles>

4-NA<smiles>O=[N+]([O-])c1cccc(/N=N/[O-])c1</smiles>

$3,3^{\prime}$-DNAB<smiles></smiles>

$4,4^{\prime}-\mathrm{DNAB}$

Scheme 1: Structure of the tested compounds and the legends.

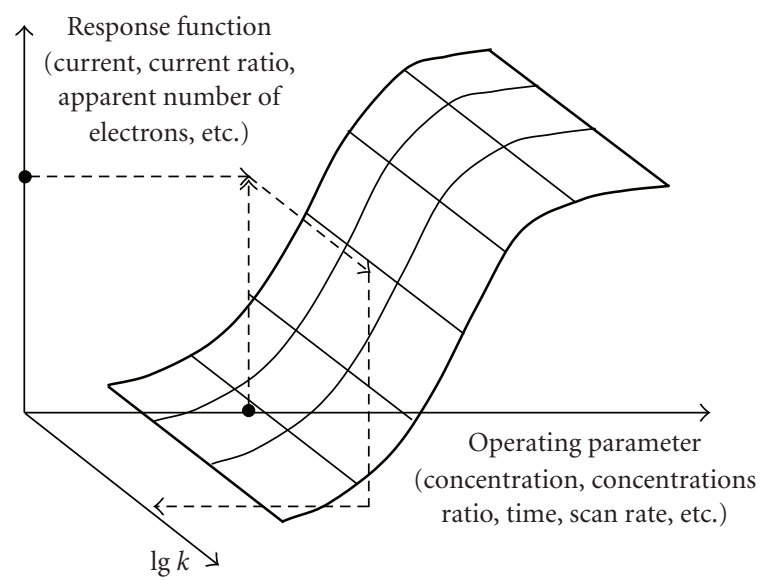

FIGURE 1: Rate constant measurements based on response function surface usage.

dependence apparent $k^{\text {prot }}$ values versus $R$ should have a descending pattern. As one may see from the Figure 2 it does not observe in the present case. The absence of remarkable effect of comproportionation reaction may be a result of joint effect of relatively low rate of this reactions and decreasing of standard potentials differences of first and second electron transfer because of hydrogen bonding $[26,27]$. The relatively low comproportionation rate constant value may be caused by high electron transfer reorganization energy, both external (because of hydrogen bonding) and internal (because of dramatic difference in structure of AR and DA of these compounds $[6,28])$. Simulation results confirm that the mentioned above changes in thermodynamics and kinetics of comproportionation reduce its effect on protonation rate constant measurements.

Quantum chemical calculations were performed at the density functional theory (DFT) level using B3LYP exchangecorrelation functional [29-31] set. The 6-311G basis set augmented by polarization and diffuse functions on all atoms were used in this study. The solvation effects (DMSO solution) were took into account within polarizable continuum model (PCM) [32-34] with the full geometry optimization. All the calculations were conducted with the GAUSSIAN 03 program package [35].

\section{Results and Discussion}

3.1. Controlled Potential Electrolysis. As known, reduction of nitroaromatic compounds can include a consecutive formation of nitroso, hydroxylamino, and amino derivatives as well as of azoxy compounds and their reduction products

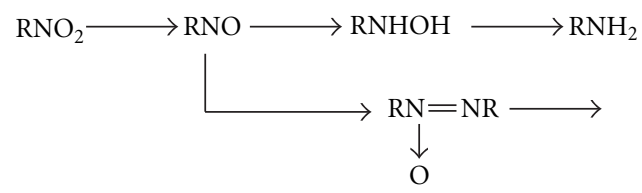




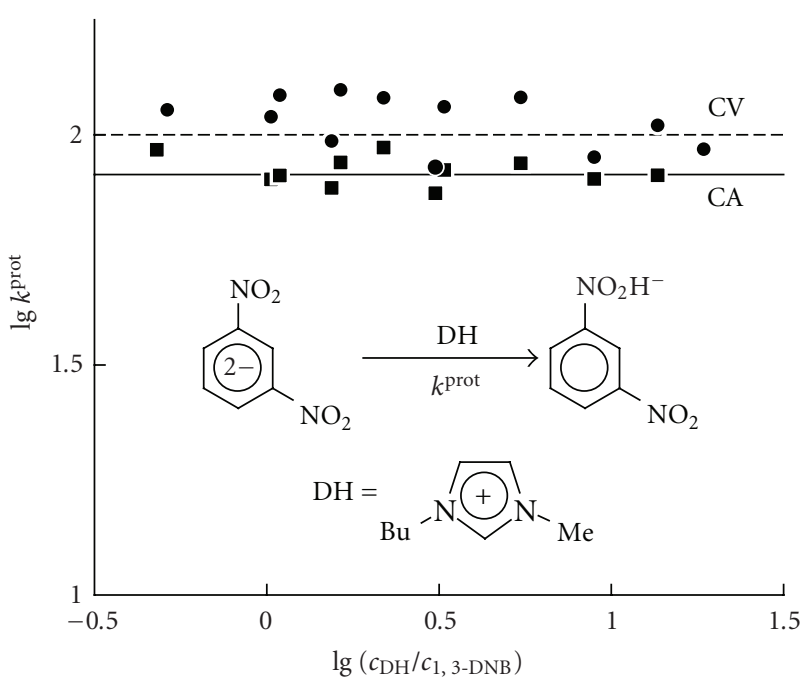

Figure 2: Dependence of the logarithm of the rate constant of 1,3-DNB dianion protonation by 1-butyl-3- methylimidazolium cations at $298 \mathrm{~K}$ in $0.1 \mathrm{M}$ solution $\mathrm{Bu} 4 \mathrm{NClO} 4$ in DMF measured by cyclic voltammetry (--) and chronoamperometry (-) at carbositall working electrode.

Reduction potentials of those compounds may lie in a broad range of values and dramatically differ from reduction potentials of the initial nitro compound. As a consequence, the potential, at which nitro compound reduction is implemented, is a crucial factor determinant for the nitro group reduction level and nature of the generated products. Therefore, we used the CV method to measure formal potentials (Table 1) of the formation of RA and DA of DNB, NNB, DNAB, NPHA, and NA isomers. The structures of these compounds are shown in Scheme 1.

Unlike DNB whose electroreduction in aprotic $[17,36-$ 38 ] and protic media [39-41] was examined in a number of researches, literature data on the electrochemical behavior of NNB and NPHA is lacking although they have been known for more than a century. As seen from Table 1, formal potentials of the formation of RA $\left(E_{1}^{0 \prime}\right)$ of $\mathrm{NNB}$ isomers are considerably (from 0.24 to $0.41 \mathrm{~V}$ ) more positive than potentials of corresponding DNB. At the same time, for these compounds the difference in formal potentials $\left(E_{2}^{0 \prime}\right)$ does not exceed $0.06 \mathrm{~V}$ by the absolute value. Hence, the ratio of DNB and NNB electroreduction potentials is similar to the relation identified for mononitro compounds. The difference in $E_{1}^{0 \prime}$ for nitro and nitroso benzenes is $0.25 \mathrm{~V}$ [42] in acetonitrile and $0.22 \mathrm{~V}$ [43] in liquid ammonia whereas $E_{2}^{0 \prime}$ values in liquid ammonia merely differ by $0.02 \mathrm{~V}$ [43].

Thus, reduction of all DNB cannot be terminated at the NNB formation step and should lead to NNB reduction products such as NPHA and DNAB. The NPHA formation in the above conditions was ascertained by the fact that the number of electrons involved in the first reduction step of 1,2-, 1,3-, and 1,4-DNB reduction in acetonitrile with benzoic acid was estimated as 4 by the coulometric method [40]. Same is evidenced by the 1,2- and 1,4-DNB electrolysis results at the potential of limiting current of the first electron transfer in the presence of benzoic acid where the key reaction products were corresponding NPHA (Table 2). Retaining of one of the nitro groups in DNB reduction in the presence of proton donors may be explained by the involvement of only the nitroso group in reduction of the process intermediates, that is NNB, at these potentials.

As seen from Table 2, NNB reduction can be accompanied by the emergence of dimeric products, that is, DNAB, in a notable amount.

Potentials of the first peaks on the CV curve for all three NPHA isomers are appreciably more negative than $E_{1}^{0 \prime}$ of corresponding DNB isomers. That is why one may expect that the electrolysis at potentials of limiting current of the first DNB reduction step will not be accompanied by further NPHA reduction. A comparison of NPHA peak potentials and $\mathrm{DNB} E_{2}^{0 \prime}$ shows that their ratio relies on the isomer structure (Table 1). Potentials of 2- and 3-NPHA peaks are somewhat more positive as compared to potentials of the formation of DA of corresponding DNB whereas 4-NPHA peak potentials are $0.25 \mathrm{~V}$ more negative than 4 -DNB $E_{2}^{0 \prime}$.

Electroreduction of 2- and 4-NPHA in the presence of proton donors, similar to NNB electroreduction, does not affect the nitro group and leads to appropriate NA. Regretfully, a close position of 3-NPHA and 3-NA reduction potentials (Table 1) does not allow identifying whether 3-NA is formed during the 3-NPHA electrolysis. Of special note is reduction of 2- and 4-NPHA to 2- and 4-NA, respectively, even in the absence of proton donors. The presence of NPHA anions in the catholyte after the exhaustive electrolysis indicates that the depolarizer molecule acts here as a proton donor by analogy with reduction of aromatic carbonic acids observed earlier in [46].

Reduction of the second nitro group could be expected as a result of the NA RA reactions. However, as seen from Table 1, formal potentials of the NA RA formation are more negative. $E_{1}^{0 \prime}$ values for 2 - and 4-NA are more negative against potentials of the first peaks on the 2- and 4-NPHA curves by 0.17 and $0.20 \mathrm{~V}$. Therefore, the formation of their RA at potentials of the DNB RA formation as a result of both the heterogeneous and homogenous electron transfer seems low probable.

In summary, the above results testify to the fact that the NA formation in DNB electroreduction is reasoned by the selective nature of reduction processes of two intermediate products, that is NNB and NPHA, generated therein. The results of the research on the general mechanism of DNB electroreduction and the selectivity causes are discussed in the below sections.

3.2. Protonation Reactions of Dinitrobenzene Radical Anions and Dianions. The most characteristic reactions of RA and DA of organic compounds are dimerization, protonation, and bond cleavage [47]. It is natural that RA and DA of nitro compounds basically can enter all of the above reactions. However, the reaction of nitro group evaluation, as it was marked for RA both of aliphatic [48] and of aromatic nitro derivatives [49], cannot be yet considered typical for nitro compounds. Meanwhile, the reaction of the 
TABLE 1: Formal potentials of the first $\left(E_{1}^{0 \prime}\right)$ and second $\left(E_{2}^{0 \prime}\right)$ electron transfer at carbositall working electrode to the tested molecules in $0.1 \mathrm{M} \mathrm{Bu}_{4} \mathrm{NClO}_{4} / \mathrm{DMF}$ relative to SCE (ferrocene oxidation potential $0.42 \mathrm{~V}$ ).

\begin{tabular}{|c|c|c|c|c|c|c|c|c|}
\hline & $E_{1}^{0^{\prime}}, \mathrm{V}$ & $E_{2}^{0 \prime}, \mathrm{V}$ & & $E_{1}^{0 \prime}, \mathrm{V}$ & $E_{2}^{0 \prime}, \mathrm{V}$ & & $E_{1}^{0^{\prime}}, \mathrm{V}$ & $E_{1}^{0 \prime}, \mathrm{V}$ \\
\hline $1,2-\mathrm{DNB}$ & -0.76 & -1.13 & 4-NNB & -0.40 & -0.93 & $3-N A$ & -1.22 & \\
\hline $1,3-\mathrm{DNB}$ & -0.85 & -1.30 & 2-NPHA & $-1.10^{*}$ & & 4-NA & -1.43 & \\
\hline $1,4-\mathrm{DNB}$ & -0.64 & -0.98 & 3-NPHA & -1.19 & & $3,3^{\prime}-\mathrm{DNAB}$ & -0.93 & -1.09 \\
\hline 2-NNB & -0.35 & $-1.15^{*}$ & 4-NPHA & $-1.23^{*}$ & & $4,4^{\prime}-\mathrm{DNAB}$ & -0.64 & -0.73 \\
\hline 3-NNB & -0.61 & -1.36 & 2-NA & -1.27 & & & & \\
\hline
\end{tabular}

* Potentials of cathode peaks on the CV curve. $E_{1}^{0 \prime}$ or $E_{2}^{0 \prime}$ were not measured since no RA and DA oxidation peaks were detected at the potential scan rate up to $100 \mathrm{~V} \mathrm{~s}^{-1}$.

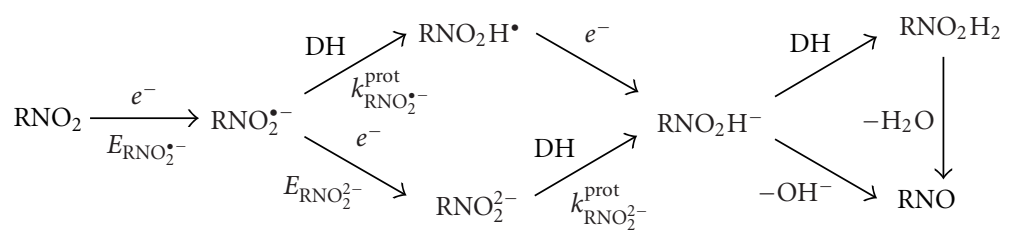

Scheme 2: Mechanism of DNB electroreduction to NNB in the conditions of the RA and DA formation.

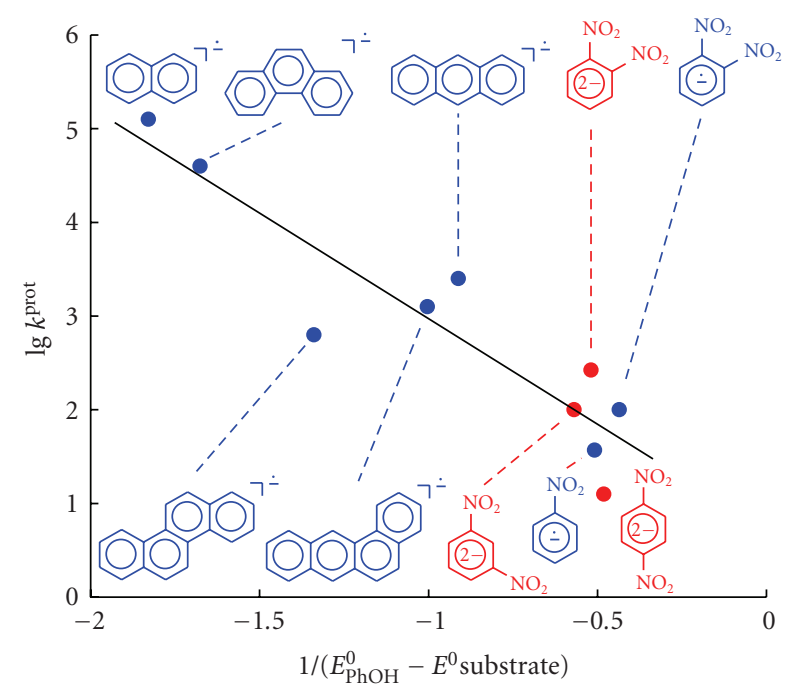

FIGURE 3: Dependence of values of rate constants of protonation of RA and DA by phenol in DMF on the difference of formal potentials of proton donor and substrate reduction. Rate constants data sources: RA naphthalene, phenathrene, chrysene, 1,2benzanthracene and anthracene [44], RA of nitrobenzene [45], and DA of 1,4-DNB, 1,3-DNB, and 1,2-DNB and RA of 1,2-DNB in this work.

dimeric products generation was not once observed for RA of aromatic mono- $[50,51]$ and polynitro compounds $[38,52]$ and for DA [51].

In our case, dependences of the limiting current values at the first and second reduction stages (CA) and currents of correspondent peaks $(\mathrm{CV})$ on the substrate concentration (in the range from 2.5 to $25 \mathrm{mmol} \cdot \mathrm{l}^{-1}$ ) for all three DNB isomers are linear both in aprotic media and in the presence of proton donors. The latter allows us to exclude the dimerization reaction from consideration and to believe
TABLe 2: Products of electrolysis ( $5 \mathrm{~mL}$ of solutions was used) at the potentials of limiting current of the first electron transfer in the presence of proton donors (DH). Yields was measured by HPLC technique.

\begin{tabular}{lccc}
\hline $\begin{array}{l}\text { Substrate } \\
\left(5 \mathrm{mmol} \cdot \mathrm{l}^{-1}\right)\end{array}$ & $\begin{array}{c}\mathrm{DH} \\
\left(50 \mathrm{mmol} \cdot \mathrm{l}^{-1}\right)\end{array}$ & $\begin{array}{c}\text { Product 1 } \\
(\text { yield })\end{array}$ & Product 2 (yield) \\
\hline 1,2-DNB & benzoic acid & 2-NPHA (64\%) & 2-NA (12\%) \\
2-NNB & $-/ /-$ & 2-NPHA (80\%) & 2-NA (6\%) \\
2-NPHA & none & $\begin{array}{c}\text { 2-NPHA anion } \\
(49 \%)\end{array}$ & 2-NA (30\%) \\
1,4-DNB & benzoic acid & 4-NPHA (88\%) & - \\
4-NNB & $-/ /-$ & 4-NPHA (28\%) & $\begin{array}{c}4,4^{\prime}-\mathrm{DNAB} \\
(48 \%)\end{array}$ \\
4-NPHA & $-/ /-$ & 4-NA (66\%) & - \\
4-NPHA & none & 4-NPHA anion & 4-NA (20\%) \\
\hline
\end{tabular}

that DNB electroreduction at potentials of both the first and the second electron transfer is described by Scheme 2 .

Scheme 2 shows that the key stage of DNB electroreduction at the first and second electron transfer potentials in the presence of proton donors is RA and DA protonation. Further transformations of its products, as mentioned above, lead to the formation of corresponding NNB.

Earlier $[4,5,7]$, we studied the kinetics of protonation reactions with the participation of various proton donors. The research results along with the literature data known to us are summarized in Table 3 . The Table shows that basicity of RA of 1,3- and 1,4-DNB is too low to measure rate constants of their protonation by aliphatic alcohols, phenol, and 1-butyl-3-methylimidazolium cations(1,3Dialkylimidazolium cations are incorporated in the most widespread ionic liquids [5] and are $\mathrm{CH}$ acids due to the proton mobility in position 2 of the imidazole ring), using the CV and CA methods. 


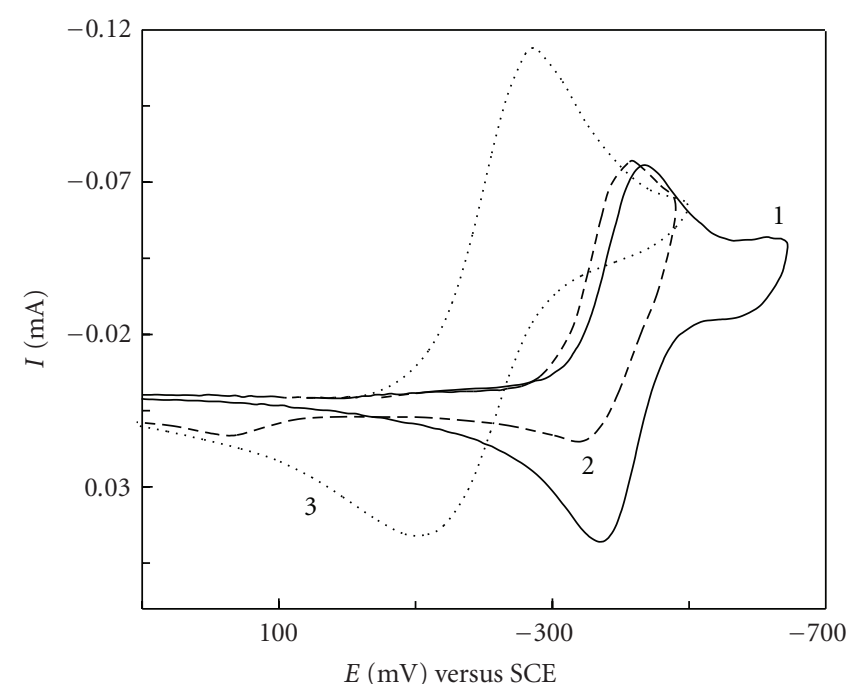

(a)

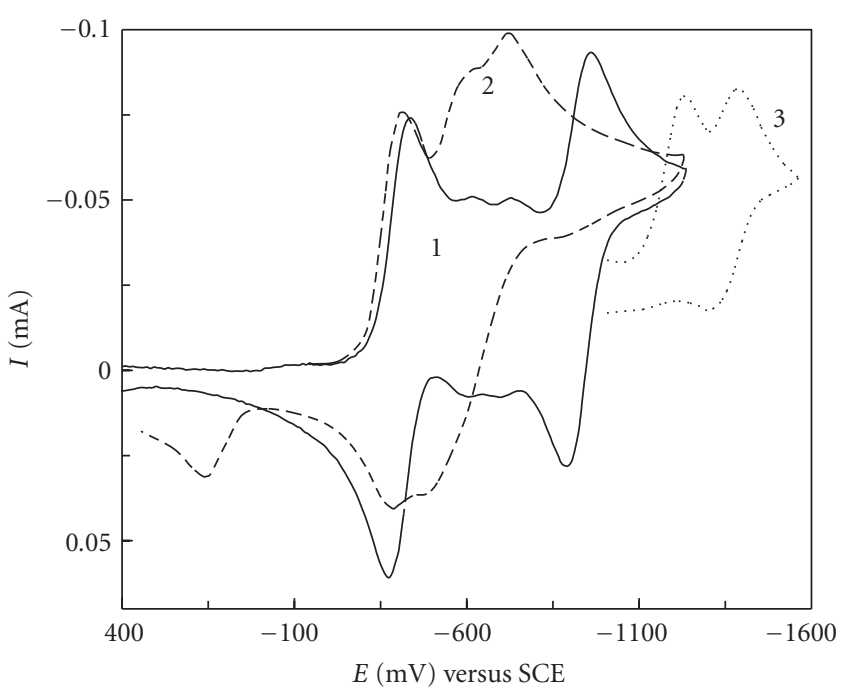

(b)

FIGURE 4: CV curves at carbositall working electrode of $5 \mathrm{mmol} \cdot \mathrm{l}^{-1} 4$-NNB DMF solution (1), in the presence of $10 \mathrm{mmol} \cdot \mathrm{l}^{-1} \mathrm{PhOH}(2)$ and $10 \mathrm{mmol} \cdot \mathrm{l}^{-1} \mathrm{BzOH}(3)$ at the scan rate $0.1 \mathrm{~V} \cdot \mathrm{s}^{-1}$ (In Figure 4(b), only the right part of curve (3) is shown).

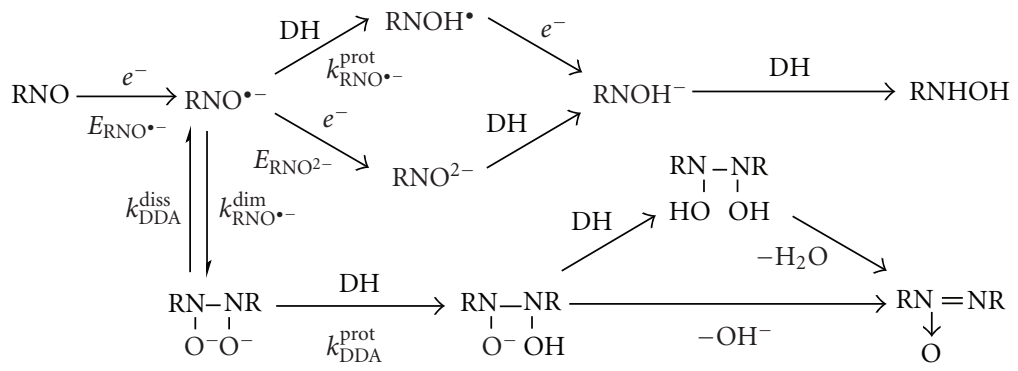

Scheme 3: Mechanism of NNB electroreduction.

Also, Table 3 provides maximal values of natural charges at oxygen atoms of the nitro group in RA and DA of DNB isomers calculated by quantum chemical methods. Of interest is that these values are rather close and lie in the $-0.68--0.71$ interval whereas rate constants of protonation of RA of DNB isomers by phenol vary over a wide range. In the case of RA, distinctions in the value of charges at the oxygen atom for the three isomers are more dramatic $(-0.50--0.64)$, yet here again, any similarity in the variations of the charge values and protonation rate constant is lacking. This gives grounds for assuming that reactions of DNB RA and DA protonation are not charge-controlled and fall to the orbital-controlled category.

According to the perturbation molecular orbital theory (PMO) [54], the rate constant of the orbital-controlled reaction should increase with a decrease in the difference of energies of reagents' frontier molecular orbitals. We demonstrated in $[47, \mathrm{ch} .3]$ that the reactivity index could be used for the quantitative evaluation of the RA protonation kinetic parameters. The index is based on the PMO theory and includes the inverse value of the difference in energies between the highest occupied molecular orbital of RA and the lowest unoccupied orbital of the proton donor. However this approach, to the best of our knowledge, has not been applied for protonation reactions of RA of nitroarenes. Also, we are not aware of whether any researches on a possibility of applying such indices to DA protonation reactions have been undertaken. Therefore, of interest was to identify to what extent reactivity indices adequately describe protonation of DNB RA and DA.

Recently, we have shown [6] that quantum chemical data on the affinity to the electron in solution of RA and DA of aromatic hydrocarbons and DNB correlates linearly with formal potentials of the first and second electron transfer to these molecules. The latter makes it possible to employ ready-available experimental values of standard potentials for computing reactivity indices and to avoid challenges [55] related to the account of solvent effect on the RA and DA electronic structure in quantum chemical calculations.

Figure 3 shows a plotted dependence of logarithm values of rate constants of protonation of RA and DA of aromatic hydrocarbons and isomeric DNB by phenol from the reverse value of the difference of formal potentials of their formation and the potential of phenol reduction (the phenol reduction formal potential was estimated from the value of its affinity to the electron using the correlation dependence obtained 
TABLE 3: Quantum chemical data on the charge density distribution in RA and DA of DNB and rate constants of their protonation by various proton donors $(\mathrm{DH})$.

\begin{tabular}{|c|c|c|c|c|c|}
\hline $\mathrm{RNO}_{2}$ & $Q_{\mathrm{RNO}_{2}^{--}}^{0, \max }$ & $Q_{\mathrm{RNO}_{2}^{2-}}^{0, \max }$ & $\mathrm{DH}$ & $\begin{array}{c}k_{\mathrm{RNO}_{2}^{--}}^{\mathrm{prot}}, \\
\mathrm{L} \mathrm{mol}^{-1} \mathrm{~s}^{-1}\end{array}$ & $\begin{array}{c}k_{\mathrm{RNO}_{2}^{2-}}^{\mathrm{prot}} \\
\mathrm{L} \mathrm{mol}^{-1} \mathrm{~s}^{-1}\end{array}$ \\
\hline $1,2-\mathrm{DNB}$ & -0.547 & -0.707 & $\begin{array}{l}\text { phenol } \\
\text { benzoic acid [39] }\end{array}$ & $\begin{array}{c}(1.03 \pm 0.13) \times 10^{2} \\
6.3 \cdot 10^{2}\end{array}$ & $\begin{array}{c}(2.65 \pm 0.60) \times 10^{2} \\
4.7 \cdot 10^{8}\end{array}$ \\
\hline \multirow{6}{*}{$1,3-\mathrm{DNB}$} & \multirow{6}{*}{-0.641} & \multirow{6}{*}{-0.679} & $\begin{array}{l}\text { phenol } \\
\text { ethanol } \\
\text { tert-butanol } \\
\text { 1-butyl-3-methyl-imidazolium cation } \\
\text { benzoic acid [39] }\end{array}$ & $\begin{array}{l}<5 \cdot 10^{-3} \\
<5 \cdot 10^{-3} \\
<5 \cdot 10^{-3} \\
<5 \cdot 10^{-3} \\
3.9 \cdot 10^{2}\end{array}$ & $\begin{array}{c}(1.1 \pm 0.1) \times 10^{2} \\
1.5 \\
1 \cdot 10^{-2} \\
82 \pm 6 \\
7.2 \cdot 10^{7}\end{array}$ \\
\hline & & & quercetin [53] & $(5.61 \pm 2.12) \times 10^{2}$ & $(5.36 \pm 2.87) \times 10^{5}$ \\
\hline & & & morin $[53]$ & $(3.37 \pm 1.28) \times 10^{5}$ & $(5.48 \pm 2.07) \times 10^{7}$ \\
\hline & & & rutin $[53]$ & $(5.61 \pm 2.12) \times 10^{2}$ & $(9.10 \pm 3.44) \times 10^{4}$ \\
\hline & & & $\beta$-carotene $[53]$ & $(5.61 \pm 2.12) \times 10^{2}$ & $(3.37 \pm 1.28) \times 10^{5}$ \\
\hline & & & ascorbic acid [53] & $(2.65 \pm 1.00) \times 10^{4}$ & $(2.03 \pm 0.77) \times 10^{8}$ \\
\hline $1,4-\mathrm{DNB}$ & -0.503 & -0.683 & phenol benzoic acid [39] & $\begin{array}{c}<5 \cdot 10^{-3} \\
670\end{array}$ & $\begin{array}{c}13 \pm 2 \\
5.5 \cdot 10^{4}\end{array}$ \\
\hline
\end{tabular}

in [6]). As you may see, the dependence is linear $\left(R^{2}=\right.$ 0.843 ), and the proposed reactivity index describes fairly the RA and DA protonation reactions. This confirms the above assumption on orbital control of the reactions.

Accordingly, here emerges an interesting, in terms of practice, and simple method to predict RA and DA protonation rate constants at the semiquantitative level basing on the parameter, which is relatively easy to determine, namely, formal potentials of substrate and proton donor reduction.

3.3. Electroreduction of Nitrosonitrobenzenes. As already noted, NNB generated by DNB reduction at the potential of the formation of RA and DA in the conditions where the latter are protonated should also reduce to RA or DA, accordingly. Indeed, DNB reduction in these conditions proceeds with consumption of more than two electrons in all cases. Therefore, it is possible to expect that the nature of the products formed in the DNB electrolysis in the presence of proton donors at limiting current potentials of the first and second electroreduction waves will be governed by NNB RA and DA reactions.

The electroreduction mechanism of aromatic nitroso compounds, particularly of nitrosobenzene, was the focus of a number of researches such as [56-59]. These have succeeded in establishing that RA of aromatic nitroso compounds undergo fast dimerization in aprotic media to yield azoxy derivatives, which, in turn, can be further reduced to azo and hydrazo derivatives [15, 60]. Electroreduction of aromatic nitroso compounds in protic media leads to $\mathrm{N}$-substituted hydroxylamines [8], and condensation of the latter with initial nitroso compounds also results in dimeric products [61].

Originating from the above, it can be anticipated that NNB electroreduction at RA formation potentials should also be complicated by dimerization processes. Indeed, at the depolarizer concentration above $1 \mathrm{mmol} \cdot \mathrm{1}^{-1}$ and potential scan rate $(v)$ below $1 \mathrm{~V} \cdot \mathrm{s}^{-1}$ the 2 -NNB anode peak that corresponds to RA oxidation is unavailable although the cathode peak height is characteristic of the one-electron process. The latter in combination with the absence of the 2-NPHA and 2-NPHA anion oxidation peaks enables to exclude the 2-NNB RA protonation reaction and to assume that 2-NNB RA enters an irreversible dimerization reaction. This is also evidenced by the fact that at $v>1 \mathrm{~V} \cdot \mathrm{s}^{-1}$ a 2$\mathrm{NNB}$ concentration increasing is accompanied by a decrease in ratio of anodic to cathodic peak currents.

Opposite to 2-NNB, anodic peaks of 3- and 4-NNB on the CV curves related to RA oxidation are observed in the overall range of values $v$ from 0.01 to $100 \mathrm{~V} \cdot \mathrm{s}^{-1}$. However, where the ratio of the phenol concentration to the substrate concentration $(R)$ is 2 the anode peaks on the CV curves related to RA oxidation actually disappear already at $v=$ $0.1 \mathrm{~V} \cdot \mathrm{s}^{-1}$ (Figure 4). The cathode peak current value does not change and oxidation peaks of corresponding NPHA and their anions do not appear. This allows the exclusion of the RA protonation reaction, in which case reduction should follow the ECE mechanism and yield NPHA. At the same time, two cathode and two anode peaks are recorded on the 3- and 4-NNB cyclic voltammograms in the presence of phenol. Their potentials coincide with the potentials of the formation and oxidation of $3,3^{\prime}-$ and $4,4^{\prime}$-DNAB RA and DA (Figure 4, Table 1). These results may be explained originating from an assumption that NNB RA dimerization is reversible, as in the case of RA of some classes of organic compounds [50,62-64], and the proton donor protonates dimeric DA [64].

Despite lower basicity of NNB RA relative to corresponding dimeric DA, at a high proton donor concentration, the protonation reaction rate can reach the value, at which it is capable to compete with dimerization. For example, at $R>10$ and $v=0.1 \mathrm{~V} \cdot \mathrm{s}^{-1}$ for 3 - and $4-\mathrm{NNB}$ or $v=1 \mathrm{~V} \cdot \mathrm{s}^{-1}$ for $2-\mathrm{NNB}$ current of the first cathodic peak begins growing with the $R$ buildup and achieves the limiting value that corresponds to the two-electron process. 


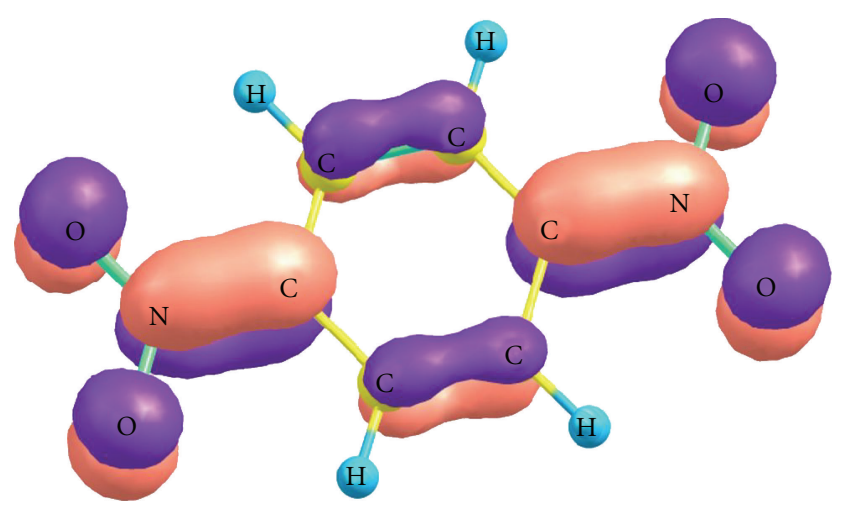

(a)

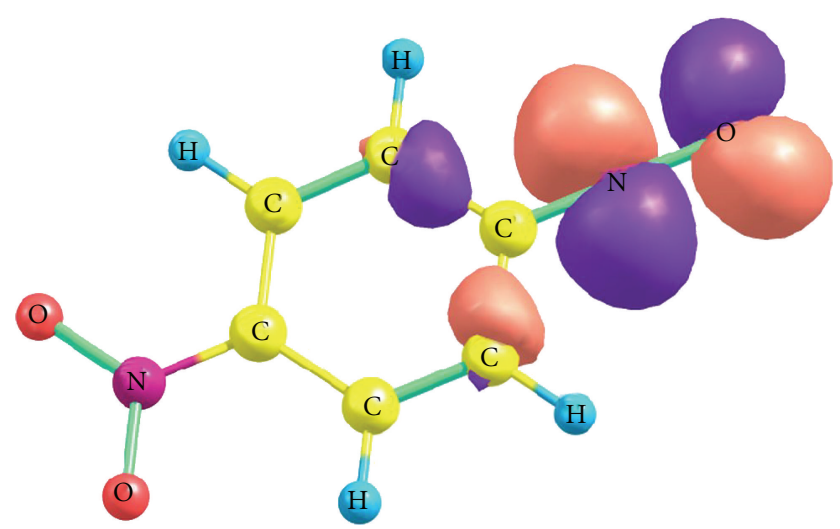

(b)

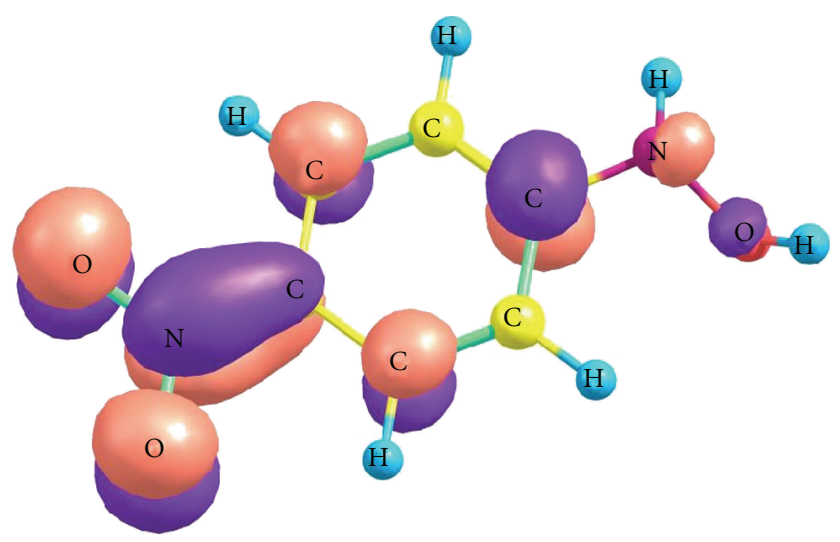

(c)

FIGURE 5: Single occupied natural orbitals (SONO) for the RA 1,4DNB (a), RA 4-NNB (b), and RA 4-NPHA (c).

Accordingly, as $R$ is increasing, DNAB first reduction peak currents gradually go down and NPHA electroreduction peak currents go up, which vividly demonstrates the ongoing competition between NNB RA dimerization and protonation reactions. Of note is that due to the competition of the dimerization reaction with NNB RA protonation, limiting currents of the cathodic peak that corresponds to the twoelectron level are afforded only at very high $R$ values. These are around 200 for less basic 4-NNB RA. At equal $R$, the highest growth of cathode peak current is observed for 2NNB, somewhat lower for 3-NNB and the lowest for 4-NNB.
TABLe 4: Spin density $(\rho)$ distribution in NNB RA.

\begin{tabular}{lcccc}
\hline \multirow{2}{*}{ RA } & \multicolumn{2}{c}{$\mathrm{NO}$} & \multicolumn{2}{c}{$\mathrm{NO}_{2}$} \\
& $\rho_{\mathrm{N}}$ & $\rho_{\mathrm{O}}$ & $\rho_{N}$ & $\rho_{O}$ \\
\hline 3-NNB & 0.381 & 0.332 & 0.014 & -0.015 \\
4-NNB & 0.685 & 0.456 & -0.059 & -0.050 \\
\hline
\end{tabular}

Thus, a decline in RA kinetic basicity was identified in the $2-\mathrm{NNB}>3-\mathrm{NNB}>4$-NNB sequence.

Should stronger acids be used, not only more basic dimeric DA is protonated but RA as well. For NNB, it means that NPHA should be generated along with DNAB. And indeed, in the presence of a 2 -fold benzoic acid, excess current of the first cathodic peak closely approaches the twoelectron level on the voltammograms of all NNB isomers at $=0.1 \mathrm{~V} \cdot \mathrm{s}^{-1}$. In parallel, the peaks whose potentials match potentials of the peaks recorded on the voltammograms for corresponding NPHA emerge in a more negative region (Figure 4). The formation of NPHA, along with DNAB, in the presence of benzoic acid is ascertained by the 4-NNB electrolysis results (Table 2).

Thus, Scheme 3 can fairly describe the general mechanism of NNB electroreduction. The scheme shows that both competing reactions-RA protonation and dimerizationinvolve merely the nitroso group and do not affect the nitro group. With a view to reveal the reasons for the selective course of these reactions, we looked at the NNB electronic structure (Figure 5(b)).

According to the quantum chemical calculations spin density $(\rho)$ in NNB RA is mainly localized on the nitroso group and is actually lacking at the nitro group (Figure 5(b) and Table 4) (according to the calculation, 2-NNB RA has a symmetric structure benzofurazane dioxide and symmetric distribution of spin density). High spin density at the nitrogen atom of the nitroso group is likely to account for the high NNB RA dimerization rate since this reaction rate rises exponentially with the $\rho$ growth [47].

Since the values of the reactivity index described in the foregoing section calculated for NNB RA protonation lie in the same range of values as for DNB, we may suppose that this reaction should also be orbital-controlled. Orbital control of protonation means that the proton is attached to the reaction center with the maximal amplitude of the frontier orbital wave function, what in the case of RA corresponds to the maximum of spin densities [47]. According to quantum chemical calculations, spin density in NNB RA is localized at the nitroso group and is actually absent at the nitro group (Figure 5(b), Table 4). That explains the experimental fact that protonation of NNB RA involves only the nitroso group and results in the NPHA formation.

3.4. Electroreduction of $\mathrm{N}$-(Nitrophenyl)-Hydroxylamines. As indicated in Section 3.1, NPHA electroreduction both in the presence of proton donors and in the aprotic solvent is accompanied by the NA formation. We showed in [3] that 


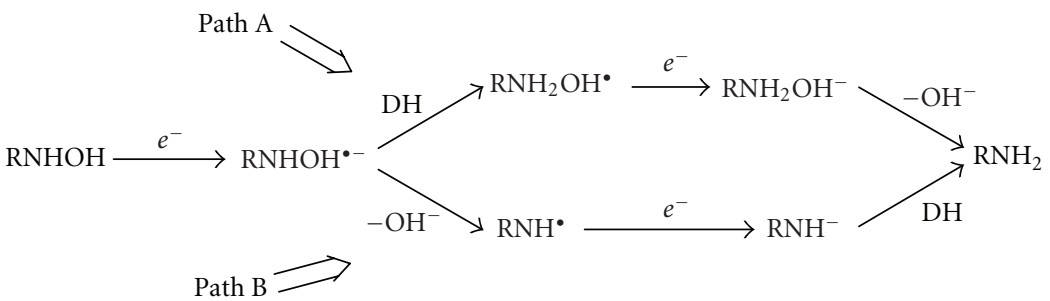

Scheme 4: Alternative mechanisms of the NPHA RA transformation to NA.

in the latter case NPHA itself acted as a proton donor and the process stoichiometry could be described by:<smiles>Nc1ccc([N+](=O)[O-])cc1</smiles>

By analogy with electroreduction of aromatic carbonic acids [46], we had assumed earlier [3] that in this case, NPHA RA was protonated by the depolarizer molecule (a socalled self-protonation reaction [65]). However data on the electronic structure of NPHA RA obtained in this research failed to confirm the assumption.

Quantum chemical calculations of NPHA RA showed that spin density therein was localized at the nitro group (Table 5). Given that in Coupman's approximation [66] frontier molecular orbitals of RA and the neutral molecule may be regarded as energy degenerated, the self-protonation reaction should be orbital controlled and proceed through the centre with maximal spin density, that is, by the nitro group rather than by the hydroxylamine one (Scheme 4, Pathway $A$ ). As this is inconsistent with the experiment (no second nitro group reduction products were identified in the ongoing microelectrolysis), assumingly, NPHA RA enter a reaction that affects the hydroxylamine group with a higher rate of nitro group protonation. Stemming from the nature of the products generated in the electrolysis at the potential of the first stage of NPHA electroreduction, we made an assumption that a reaction of hydroxide anion elimination from NPHA RA may occur here (Scheme 4, Pathway B). A similar N-O bond cleavage was observed for RA oximes earlier [67].

Quantum chemical calculations show that the hydroxide anion elimination reaction in the NPHA RA is a thermodynamically favorable process (Table 5). The activation energies are nearly the same for all the NPHA RA isomers within computational error, and they are approximately 1.5 times lower than the activation energy of bromide anion elimination from the RA of 4-nitrobenzylbromide (Table 5) with $\lg k=5.7$ [68]. That gives grounds for assuming that the rate of hydroxide anion elimination in NPHA RA can really be rather high and achieve $10^{7}-10^{8} \mathrm{~s}^{-1}$.

In summary, there are reasons to suppose that the mechanism of NPHA reduction to NA is described by Pathway $B$ (Scheme 4). A theoretical model that describes
TABle 5: Spin density $(\rho)$ distribution in NPHA RA, free energy $(\Delta G)$ and activation energy $\left(E_{a}\right)$ of the $\mathrm{OH}$ anion split-off.

\begin{tabular}{|c|c|c|c|c|c|c|}
\hline \multirow{2}{*}{ RA } & \multicolumn{2}{|c|}{$\mathrm{NO}_{2}$} & \multicolumn{2}{|c|}{$\mathrm{NHOH}$} & \multirow{2}{*}{$\begin{array}{c}\Delta G, \\
\mathrm{kcal} \cdot \\
\mathrm{mol}^{-1}\end{array}$} & \multirow{2}{*}{$\begin{array}{c}E_{\mathrm{a}} \\
\mathrm{kcal} \cdot \\
\mathrm{mol}^{-1}\end{array}$} \\
\hline & $\rho_{\mathrm{N}}$ & $\rho_{\mathrm{O}}$ & $\rho_{\mathrm{N}}$ & $\rho_{\mathrm{O}}$ & & \\
\hline 2-NPHA & 0.338 & 0.233 & 0.027 & 0.006 & -4.9 & 9.0 \\
\hline 3-NPHA & 0.320 & 0.221 & -0.001 & -0.002 & -3.5 & 10.0 \\
\hline \multirow{2}{*}{$\begin{array}{l}\text { 4-NPHA } \\
\mathrm{CH}_{2} \mathrm{Br}\end{array}$} & 0.333 & 0.215 & 0.018 & 0.008 & -5.2 & 8.1 \\
\hline & - & - & - & - & - & 14.0 [68] \\
\hline $\mathrm{NO}_{2}$ & & & & & & \\
\hline
\end{tabular}

impact of the RA structure on the bond cleavage rate was proposed by us earlier (ch. 3 in [47]).

\section{Conclusions}

The mechanism of electrochemical reduction of dinitrobenzenes in DMF in the presence of controlled amounts of proton donors was studied by the methods of cyclic voltammetry, chronoamperometry, and controlled potential electrolysis.

It has been stated that electroreduction proceeds selectively and incorporates consecutive steps of the formation of nitrobenzene nitroso, hydroxylamino, and amino derivatives. It has been shown that the reaction of NNB RA dimerization that competes with their protonation reaction is reversible. The comparison of experimental data with the results of quantum chemical calculations allowed the assumption on the process selectivity being conditioned by the fact that NNB RA protonation occurs at the nitroso group and leads to corresponding NPHA whose RA are unstable and decompose with the hydroxide anion split-off. It should be highlighted that it is the first example of the hydroxide anion split-off from RA of hydroxylamines.

\section{Acknowledgment}

This work was carried out in the framework of the Federal Target Program "Scientific and Pedagogical Professional Community of Innovation Russia” for 2009-2013. 


\section{References}

[1] D. H. Evans, "One-electron and two-electron transfers in electrochemistry and homogeneous solution reactions," Chemical Reviews, vol. 108, no. 7, pp. 2113-2144, 2008.

[2] Z. V. Todres, Ion-Radical Organic Chemistry: Principles and Applications, CRC Press, Taylor \& Francis Group, Boca Raton, Fla, USA, 2nd edition, 2009.

[3] M. A. Syroeshkin, A. S. Mendkovich, L. V. Mikhalchenko, A. I. Rusakov, and V. P. Gul'tyai, "Self-protonation upon the electroreduction of 2- and 4-nitrophenylhydroxylamines in aprotic media," Mendeleev Communications, vol. 19, no. 5, pp. 258-259, 2009.

[4] M. A. Syroeshkin, A. S. Mendkovich, L. V. Mikhal'Chenko, A. I. Rusakov, and V. P. Gul'tyai, "Kinetics of protonation of the 1,2-dinitrobenzene radical anion and dianion by phenol," Russian Chemical Bulletin, vol. 58, no. 2, pp. 468-472, 2009.

[5] L. V. Mikhalchenko, A. S. Mendkovich, M. A. Syroeshkin, and V. P. Gul'tyai, "Kinetics of the 1,3-dinitrobenzene dianion protonation with 1-butyl-3-methylimidazolium cations," Mendeleev Communications, vol. 19, no. 2, pp. 96-98, 2009.

[6] M. A. Syroeshkin, M. N. Mikhailov, A. S. Mendkovich, and A. I. Rusakov, "On the multiplicity of cathodically generated dianions of dinitrobenzenes," Russian Chemical Bulletin, vol. 58, no. 1, pp. 41-46, 2009.

[7] A. S. Mendkovich, M. A. Syroeshkin, L. V. Mikhalchenko, A. I. Rusakov, and V. P. Gultyai, "Protonation of 1,3- and 1,4dinitrobenzene dianions," Russian Chemical Bulletin, vol. 57, no. 7, pp. 1492-1495, 2008.

[8] A. J. Fry, "The electrochemistry of nitro, nitroso, and related compounds," in Supplement F2: The Chemistry of Amino, Nitroso, Nitro and Related Groups, S. Patai, Ed., p. 837, John Wiley \& Sons, Chichester, UK, 1996.

[9] J. D. Rodgers and N. J. Bunce, "Electrochemical treatment of 2,4,6-trinitrotoluene and related compounds," Environmental Science and Technology, vol. 35, no. 2, pp. 406-410, 2001.

[10] P. Selvam, S. K. Mohapatra, S. U. Sonavane, and R. V. Jayaram, "Chemo- and regioselective reduction of nitroarenes, carbonyls and azo dyes over nickel-incorporated hexagonal mesoporous aluminophosphate molecular sieves," Tetrahedron Letters, vol. 45, no. 9, pp. 2003-2007, 2004.

[11] S. A. Shevelev, A. K. Shakhnes, B. I. Ugrak, and S. S. Vorob'ev, "Highly selective one-step synthesis of 2-amino-4,6dinitrotoluene and 2,6-diamino-4-nitrotoluene from 2,4,6trinitrotoluene," Synthetic Communications, vol. 31, no. 17, pp. 2557-2561, 2001.

[12] S. E. Barrows, C. J. Cramer, D. G. Truhlar, M. S. Elovitz, and E. J. Weber, "Factors controlling regioselectivity in the reduction of polynitroaromatics in aqueous solution," Environmental Science and Technology, vol. 30, no. 10, pp. 3028-3038, 1996.

[13] M.-J. Huang and J. Leszczynski, "The mechanism of the radical-anion reduction of 2,4,6-trinitrotoluene: a theoretical insight," Journal of Molecular Structure, vol. 592, pp. 105-113, 2002.

[14] V. N. Leibzon, L. V. Michalchenko, M. Yu. Leonova, and V. P. Gultyai, "Change in regioselectivity in the monoreduction of 2,4,6-trinitrotoluene with titanium(III) and vanadium(II) ions in the presence of iron(II) and copper(II) salts," Russian Chemical Bulletin, vol. 54, no. 5, pp. 1203-1207, 2005.

[15] J. Grimshaw, Electrochemical Reactions and Mechanisms in Organic Chemistry, Elsevier, Tokyo, Japan, 2000.

[16] S. E. Panicheva and B. K. Filanovskii, "Comparison of glassycarbon and carbosital electrodes in electrochemical stripping analysis," Industrial Laboratory, vol. 55, no. 5, pp. 519-521, 1989.

[17] N. A. Macías-Ruvalcaba and D. H. Evans, "Study of the effects of ion pairing and activity coefficients on the separation in standard potentials for two-step reduction of dinitroaromatics," Journal of Physical Chemistry B, vol. 109, no. 30, pp. 14642-14647, 2005.

[18] N. G. Tsierkezos, "Cyclic voltammetric studies of ferrocene in nonaqueous solvents in the temperature range from 248.15 to 298.15 K," Journal of Solution Chemistry, vol. 36, no. 3, pp. 289-302, 2007.

[19] E. B. Melnikov, G. A. Suboch, and E. Y. Belyaev, "Tungsten compounds-catalyzed oxidation of primary aromatic amines," Russian Journal of Organic Chemistry, vol. 31, p. 1849, 1995.

[20] F. Y. Alway, "Meta-nitro-nitrosobenzol," Berichte der Deutschen Chemischen Gesellschaft, vol. 36, no. 2, pp. 2530-2531, 1903.

[21] J. McIntyre and J. C. E. Simpson, "Cinnolines and other heterocyclic types in relation to the chemotherapy of trypanosomiasis-part V: quaternary salts of 4:4' -bismethylamino-6: 6'-azocinnoline," Journal of the Chemical Society, pp. 26152616, 1952.

[22] R. Kuhn and F. Weygand, " $o$ - und p-nitro-phenylhydroxylamin," Berichte der Deutschen Chemischen Gesellschaft, vol. 69, pp. 1969-1974, 1936.

[23] K. Brand, "Die Partielle Reduction aromatischer Dinitround Polynitro-Verbindungen auf electrochemischem Wege. I. Mittheilung," Berichte der Deutschen Chemischen Gesellschaft, vol. 4, p. 4006, 1905.

[24] http://www.elchsoft.com/DigiElch/Default.aspx.

[25] Z. Rongfeng and D. H. Evans, "The current for a twoelectron reaction is not necessarily twice that of a one-electron reaction," Journal of Electroanalytical Chemistry, vol. 385, no. 2, pp. 201-207, 1995.

[26] M. Svaan and V. D. Parker, "The association reaction of ion radicals with neutral molecules. V: hydrogen bonding equilibria between anion radicals of substituted nitrobenzenes and benzophenones with hydroxylic compounds," Acta Chemica Scandinavica B, vol. 40, pp. 36-39, 1986.

[27] M. A. Syroeshkin, A. S. Mendkovich, L. V. Mikhal'chenko, and V. P. Gul'tyai, "The nature of associates of 1,4-dinitrobenzene dianion with 1-butyl-3-methylimidazolium and 1-butyl-2,3dimethylimidazolium cations," Russian Chemical Bulletin, vol. 58, pp. 1688-1693, 2009.

[28] M. N. Mikhailov, A. S. Mendkovich, M. B. Kuzminsky, and A. I. Rusakov, "A multiconfigurational study of anion-radical and dianion of 1,3-dinitrobenzene," Journal of Molecular Structure, vol. 847, no. 1-3, pp. 103-106, 2007.

[29] A. D. Becke, "Density-functional thermochemistry. III. The role of exact exchange," The Journal of Chemical Physics, vol. 98, no. 7, pp. 5648-5652, 1993.

[30] C. Lee, W. Yang, and R. G. Parr, "Development of the ColleSalvetti correlation-energy formula into a functional of the electron density," Physical Review B, vol. 37, no. 2, pp. 785$789,1988$.

[31] S. H. Vosko, L. Wilk, and M. Nusair, "Accurate spin-dependent electron liquid correlation energies for local spin density calculations: a critical analysis," Canadian Journal of Physics, vol. 58 , no. 8 , pp. $1200-1211,1980$.

[32] J. Tomasi and M. Persico, "Molecular interactions in solution: an overview of methods based on continuous distributions of the solvent," Chemical Reviews, vol. 94, no. 7, pp. 2027-2094, 1994. 
[33] E. Cancès, B. Mennucci, and J. Tomasi, "A new integral equation formalism for the polarizable continuum model: theoretical background and applications to Isotropic and anisotropic dielectrics," Journal of Chemical Physics, vol. 107, no. 8, pp. 3032-3041, 1997.

[34] V. Barone and M. Cossi, "Quantum calculation of molecular energies and energy gradients in solution by a conductor solvent model," Journal of Physical Chemistry A, vol. 102, no. 11, pp. 1995-2001, 1998.

[35] M. J. Frisch, G. W. Trucks, H. B. Schlegel et al., GAUSSIAN 03, Revision B.03, Gaussian, Inc., Pittsburgh, Pa, USA, 2003.

[36] H. Bock and U. Lechner-Knoblauch, "The electrochemical reduction of aromatic nitrocompounds in aprotic solution," Zeitschrift für Naturforschung, vol. 40, pp. 1463-1475, 1985.

[37] C. Chan-Leonor, S. L. Martin, and D. K. Smith, "Electrochemically controlled hydrogen bonding. Redox-dependent formation of a 2:1 diarylurea/dinitrobenzene2- complex," Journal of Organic Chemistry, vol. 70, no. 26, pp. 10817-10822, 2005.

[38] N. A. Macías-Ruvalcaba, J. P. Telo, and D. H. Evans, "Studies of the electrochemical reduction of some dinitroaromatics," Journal of Electroanalytical Chemistry, vol. 600, no. 2, pp. 294302, 2007.

[39] M. Mohammad, M. S. Subhani, W. Begum et al., "Protonation of anion radicals and dianions of some dinitro aromatics," Research on Chemical Intermediates, vol. 16, pp. 29-43, 1991.

[40] P. D. Jannakoudakis and E. Theodoridou, "Reduktion der Dinitrobenzole an Kohlenstoff-Faser-Electroden in Acetonitril ohne und mit Protonendonatoren," Zeitschrift für Physikalische Chemie, vol. 130, p. 167, 1982.

[41] H. Wang and V. D. Parker, "The effect of the substitution pattern on the protonation pathways of dinitrobenzene dianions in N,N-dimethylformamide solution," Acta Chemica Scandinavica, vol. 48, pp. 933-936, 1994.

[42] T. Ohba, H. Ishida, T. Yamaguchi, T. Horiuchi, and K. Ohkubo, "Carbon dioxide-promoted electrochemical reduction of aromatic nitro compounds to azoxy compounds in acetonitrile," Journal of the Chemical Society, Chemical Communications, no. 3, pp. 263-264, 1994.

[43] W. H. Smith and A. J. Bard, "Electrochemical reactions of organic compounds in liquid ammonia. II. Nitrobenzene and nitrosobenzene," Journal of the American Chemical Society, vol. 97, no. 18, pp. 5203-5210, 1975.

[44] M. F. Nielsen and O. Hammerich, "The protonation of the anthracene anion radical in dimethyl sulfoxide using phenol and the phenol/phenolate complex as proton sources: a well behaved process," Acta Chemica Scandinavica, vol. 43, pp. 269 274, 1989 .

[45] A. S. Mendkovich, V. N. Leibzon, and L. V. Martynova, "Use of current-time curves for determining the mechanism of electrode processes-decay of a radical formed upon protonation of the radical-anion of nitrobenzene," Soviet Electrochemistry, vol. 18, p. 375, 1982.

[46] A. S. Mendkovich, O. Hammerich, T. Ya. Rubinskaya, and V. P. Gultyai, "Self-protonation reaction of simple aromatic carboxylic acids during voltammetric reduction in dimethyl sulfoxide," Acta Chemica Scandinavica, vol. 45, pp. 644-651, 1991.

[47] A. I. Rusakov, A. S. Mendkovich, V. P. Gul'tyai, and V. Yu. Orlov, Struktura i Reaktsionnaya Sposobnost. Organicheskikh Anion-Radikalov, Mir, Moscow, Russia, 2005.

[48] V. N. Leibzon, A. S. Mendkovich, S. G. Mairanovskii et al., "On the one-electron stage at electroreduction tertiary aliphatic nitrocompounds in water medium," Doklady Akademii Nauk SSSR, vol. 229, p. 1378, 1976.

[49] C. D. Stevenson, P. M. Garland, and M. L. Batz, "Evidence of carbenes in the explosion chemistry of nitroaromatic anion radicals," Journal of Organic Chemistry, vol. 61, no. 17, pp. 5948-5952, 1996.

[50] O. Hammerich and V. D. Parker, "The kinetics and mechanism of the reversible dimerization of anthracene anion radicals substituted with electron withdrawing substituents," Acta Chemica Scandinavica B, vol. 35, p. 341, 1981.

[51] A. S. Mendkovich, L. V. Michalchenko, and V. P. Gultyai, "Study of the reactions of 9-nitroanthracene anion radicals and dianions in dimethylformamide by the controlled potential constant-voltage electrolysis method," Journal of Electroanalytical Chemistry, vol. 224, no. 1-2, pp. 273-275, 1987.

[52] I. Gallardo, G. Guirado, J. Marquet, and N. Vilà, "Evidence for a $\pi$ dimer in the electrochemical reduction of 1,3,5trinitrobenzene: a reversible N2-fixation system," Angewandte Chemie International Edition, vol. 46, no. 8, pp. 1321-1325, 2007.

[53] N. Arshad, N. K. Janjua, S. Ahmed, A. Y. Khan, and L. H. Skibsted, "Electrochemical investigations of antioxidant interactions with radical anion and dianion of 1,3-dinitrobenzene," Electrochimica Acta, vol. 54, no. 26, pp. 6184-6189, 2009.

[54] G. Klopman, Chemical Reactivity and Reaction Paths, John Wiley \& Sons, New York, NY, USA, 1974.

[55] P. Jaramillo, P. Pérez, P. Fuentealba, S. Canuto, and K. Coutinho, "Solvent effects on global reactivity properties for neutral and charged systems using the sequential monte carlo quantum mechanics model," Journal of Physical Chemistry B, vol. 113, no. 13, pp. 4314-4322, 2009.

[56] M. Lipsztajn, T. M. Krygowski, E. Laren, and Z. Galus, "Electrochemical investigations of intermediates in electroreduction of aromatic nitro and nitroso compounds in N,Ndimethylformamide Part II. electrochemical behaviour of nitrosobenzene," Journal of Electroanalytical Chemistry, vol. 57, no. 3, pp. 339-350, 1974.

[57] E. Steudel, J. Posdorfer, and R. N. Schindler, "Intermediates and products in the electrochemical reduction of nitrosobenzene. A spectroelectrochemical investigation," Electrochimica Acta, vol. 40, no. 11, pp. 1587-1594, 1995.

[58] L. J. Núñez-Vergara, J. A. Squella, C. Olea-Azar, S. Bollo, P. A. Navarrete-Encina, and J. C. Sturm, "Nitrosobenzene: electrochemical, UV-visible and EPR spectroscopic studies on the nitrosobenzene free radical generation and its interaction with glutathione," Electrochimica Acta, vol. 45, no. 21, pp. 3555-3561, 2000.

[59] M. R. Asirvatham and M. D. Hawley, "Electron-transfer processes The electrochemical and chemical behavior of nitrosobenzene," Journal of Electroanalytical Chemistry, vol. 57, no. 2, pp. 179-190, 1974.

[60] M. Lipsztajn, T. M. Krygowski, E. Laren, and Z. Galus, "Electrochemical investigations of intermediates in electroreduction of aromatic nitro and nitroso compounds in DMFpart I: electrochemical behaviour of azoxybenzene," Journal of Electroanalytical Chemistry, vol. 54, no. 2, pp. 313-320, 1974.

[61] P. Zuman and Z. Fijaiek, "Reaction of electrogenerated arylhydroxylamines and nitrosobenzene in the course of reduction of nitrobenzene under conditions of cyclic voltammetry," Journal of Electroanalytical Chemistry, vol. 296, no. 2, pp. 589-593, 1990. 
[62] C. Amatore, J. Pinson, and J. M. Savéant, "Are anion radicals unable to undergo radical-radical dimerization?" Journal of Electroanalytical Chemistry, vol. 137, no. 1, pp. 143-148, 1982.

[63] O. Hammerich and V. D. Parker, "Are low or negative activation enthalpies consistent with the alleged one step mechanism for the dimerization of 9-substituted anthracene anion radicals?" Acta Chemica Scandinavica, vol. 37, pp. 379392, 1983.

[64] C. Costentin and J.-M. Savéant, "Dimerization of electrochemically generated ion radicals: mechanisms and reactivity factors," Journal of Electroanalytical Chemistry, vol. 564, no. 12, pp. 99-113, 2004.

[65] C. Amatore, G. Capobianco, G. Farnia et al., "Kinetics and mechanism of self-protonation reactions in organic electrochemical processes," Journal of the American Chemical Society, vol. 107, no. 7, pp. 1815-1824, 1985.

[66] T. Koopmans, "Ordering of wave functions and eigenvalues to the individual electrons of an atom," Physica, vol. 1, pp. 104113,1933

[67] B. Soucaze-Guillous and H. Lund, "Electrochemical reduction of oximes in aprotic media," Acta Chemica Scandinavica, vol. 52, no. 4, pp. 417-424, 1998.

[68] M. Meot-Ner, P. Neta, R. K. Norris, and K. Wilson, "Temperature effects on rates of dehalogenation of aromatic anion radicals," Journal of Physical Chemistry, vol. 90, no. 1, pp. 168173, 1986. 


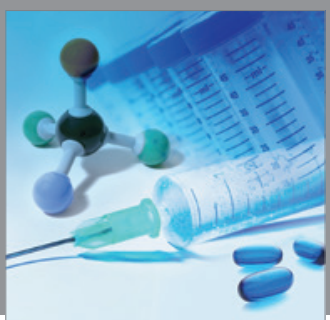

International Journal of

Medicinal Chemistry

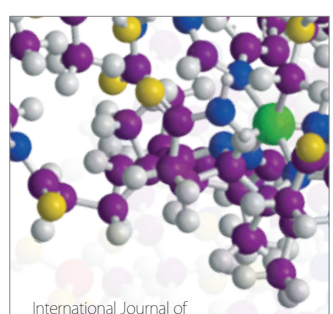

Carbohydrate Chemistry

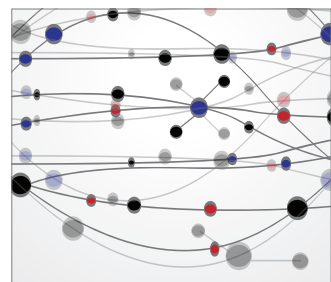

The Scientific World Journal
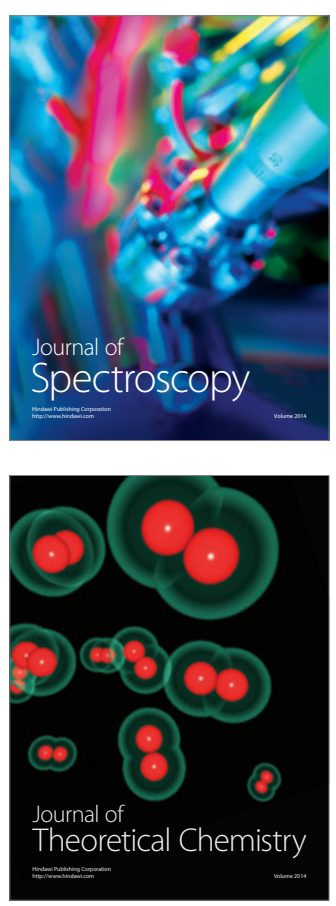
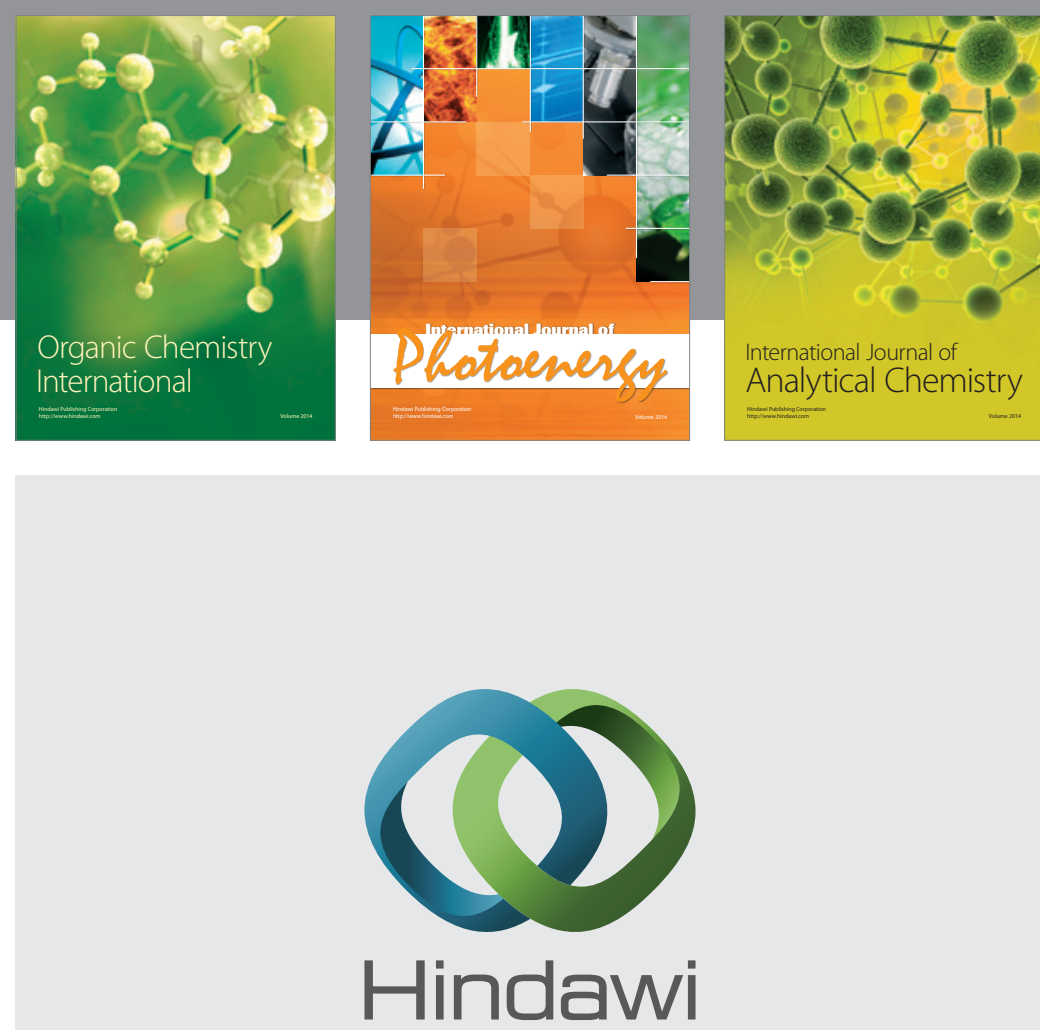

Submit your manuscripts at

http://www.hindawi.com
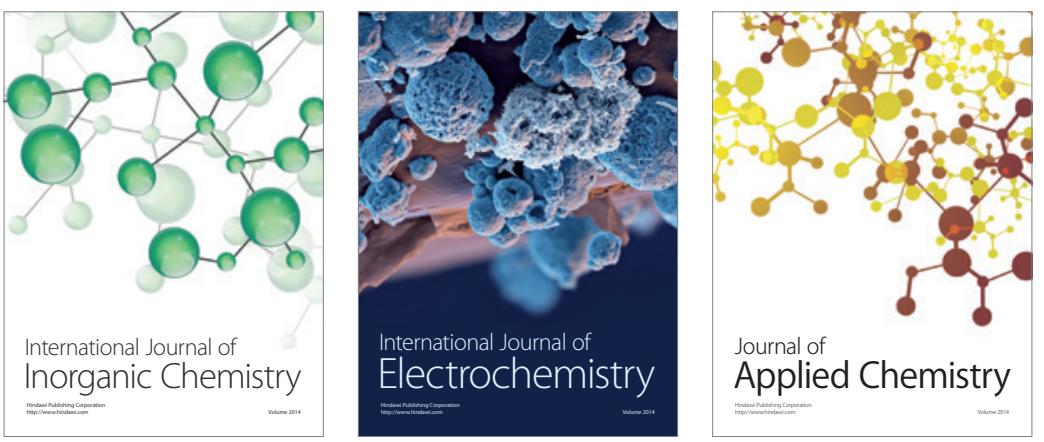

Journal of

Applied Chemistry
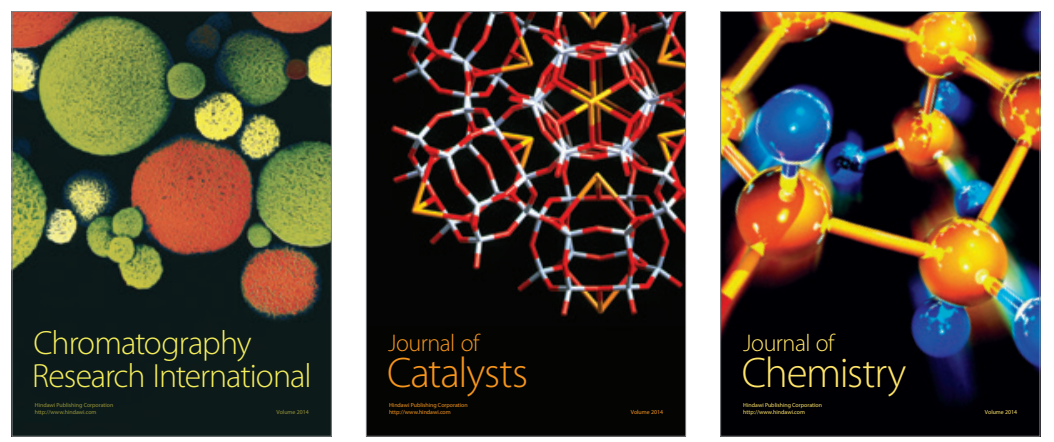
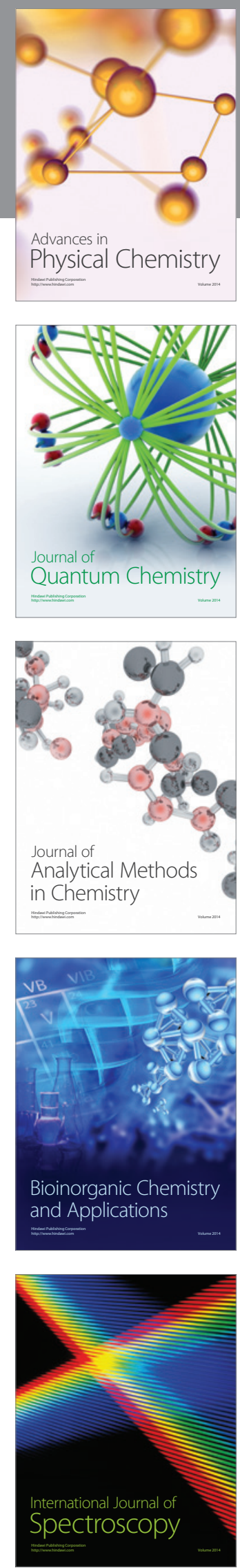